\title{
Protest Movements in Asylum and Deportation
}

\author{
Sieglinde Rosenberger / Verena Stern / Nina Merhaut (Eds.) \\ Cham/Heidelberg/New York/Dordrecht/London 2018: Springer, 294 Seiten.
}

Dr. Felix Butzlaff

Institut für Gesellschaftswandel und Nachhaltigkeit (IGN), Wirtschaftsuniversität Wien

E-Mail: felix.butzlaff@wu.ac.at

The edited volume "Protest Movements in Asylum and Deportation" by Sieglinde Rosenberger, Verena Stern and Nina Merhaut sets out to compare movements and mobilizations in Austria Switzerland, Germany that target asylum politics, centers, deportations etc.. Based on a three-year comparative study on anti-deportation protests in those three countries, it goes well beyond the scope of the original research project in addressing more diverse types of mobilizations - solidarity movements as well as refugee activism or right-wing mobilizations against asylum centers. The book departs from the observation that protest activities in general and especially with regard to the highly polarizing issue of asylum politics, refugees and migration, have increased heavily - and that often enough they are driven and organized by similar actor types. The edited volume seeks to combine different angles on the subject and assembles chapters using comparative perspectives as well as analyzing national developments or even case studies all pursuing a set of underlying research questions: how and why protests occur, how actors engage with or resist the reception of asylum seekers. Furthermore, special consideration is given to the organization of protests, actor networks and the ties of protest groups to state actors and institutions.

The structure and sequence of contributions are designed in a convincing and plausible manner: an extensive and thorough introduction by Sieglinde Rosenberger is followed by three articles that contextualize protests in the realm of asylum and migration politics in the respective three countries. Afterwards, three perspectives of protest are distinguished and treated in three chapters each: solidarity movements against deportation
(Part III, chapters 5-7), refugee activism for inclusion (part IV, chapters 8 - IO) as well as restrictive protests against asylum seekers and their reception (part V, chapters II and I2). Part VI then pulls the strings together and looks for the impact on the different political cultures and constellations. One of the book's greatest merits is that it includes the anti-asylum protests that have so often been ignored by social movement scholars concentrating on progressive and left-wing mobilizations. This way, it delivers an extensive portray of the polarized protest landscape flourishing throughout the last years in three European countries through a variety of lenses and in great detail and analytical rigor.

The book sets out from a justification of the use of the term political protest over social movement. This is in part understandable as it is often very diverse, heterogeneous and small groups at the local level that mobilize pro/contra asylum seekers. On the one hand, these groups often lack the organizational structure and stability over time to justify that one calls them a social movement in the first place- which makes this a plausible argument. On the other hand, however, protest groups in the realm of asylum and migration - whether in favor or against - portray themselves often as part of a social movement. And while this can be a strategy to claim popular legitimacy, it furthermore shows a) how protests groups perceive themselves and claim to represent far greater parts of the population and b) that as local activists they are still embedded in networks and debates that go far beyond the local contexts but seek policy changes at the national or international level. Dieter Rucht underlines this perspective in his contribution on the "Mobilization Against Refugees and Asylum Seekers 
in Germany: A Social Movement Perspective" (chapter II: 225-245): that the importance of organizational networks as well as discourse coalitions for protest mobilizations can hardly be overrated.

Rosenberger and Haselbacher in their analysis of asylum-center-protest in Austria locate these movements as a "movement from above" (265), which heavily rely on access to institutions and ties to political actors and representatives. Protest and social movements in many ways have not only been normalized in the view of most people, but also firmly integrated into the political strategy repertoire of parties, institutions and other political actors. This tells much about a possibly changing role of movement or protest mobilizations that comes with normalization: that the legitimation potential of extra-institutional protest as being uncorrupted by the logics of the party system cannot be taken for granted anymore, but might indeed often be quite the opposite. Rosenberger and Haselbacher as well as the edited volume as a whole do ask these questions - by stating that asylum-center-protest as well as solidarity or migrant protests are occurring with rising frequencies and changing the movement landscapes in their respective countries. However, they do not follow up on these observations with regard to the implications for democracy and the democratic expectations of citizens.

A further contextualization with regard to a political culture and climate of protest, mobilization and critique of representative democracy would have been helpful - even more so as this is specifically stated as a goal in the book's introduction. Especially the focus on organizational ties, actor networks, protest repertoires etc. tends to overlook changes and developments in protest and movement cultures that make people distrust political representatives and join protest mobilizations that would have remained silent a couple of years ago. In the volume's structure, this perspective remains comparatively underdeveloped as actor motivations, biographies and perceptions of democracy are not explicitly targeted.

Regardless of the aforementioned weaknesses (or rather not fully developed potentials) the volume constitutes a highly valuable contribution to shifting constellations of social mobilizations in contemporary Europe. Especially the varying degrees of institutions and political actors making strategic use of protest potential in the field of asylum and migration politics show, how previously separated realms of politics and political science (i.e. established institutions on the one hand, social movements on the other) intertwine more and more and call for scientific approaches that are able to productively combine methods and perspectives. 